\title{
IDENTIFIKASI BUMBU KHAS TRADISIONAL BALI PADA DESA BALI AGA DI KABUPATEN BULELENG
}

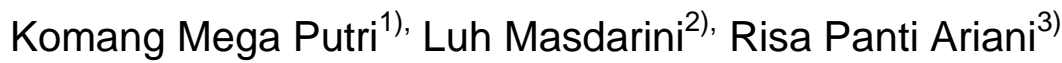 \\ Program studi pendidikan kesejahteraan keluarga \\ universitas pendidikan ganesha \\ Singaraja, Indonesia \\ e-mail: komangmegaputri98@gmail.com, masdarini@undiksha.ac.id, \\ risa.panti@undiksha.ac.id
}

\begin{abstract}
Abstrak
Penelitian ini bertujuan untuk mendeskrisikan bumbu tradisional Bali pada Desa Bali Aga di Kabupaten Buleleng bumbu-bumbu yang digunakan pada makanan khas dan makanan sehari-hari. Jenis penelitian ini yaitu deskriftif dan berlokasi pada Desa Bali Aga Di Kabupaten Buleleng. Teknik Pemilihin informan yaitu (1) Pusposive Sampling dan (2) Random Sampling. Teknik pengumpulan data dengan metode (1) observasi dan (2) wawancara, sedangkan instrument penelitian yang digunakan yaitu (1) lembar observasi dan (2) panduan wawancara. Analisis data menggunakan teknik deskriftif kualitatuf. Hasil Penelitian ini menunjukan bahwa bumbu tradisional pada Desa Bali Aga di Kabupaten Buleleng yaitu dari Base gede/wayah, base selem, base bawang jahe, base colok, base manis, sambal mba, sambal nyuh ,basan ketekan (wewalungan), basan ketekan (isin bet/alas), base pengenep, base uyah sere tabia, base sune cekuh, base pelalah, base kables, base plecing, base serosop, base kela, dan base nyangluh.
\end{abstract}

Kata-kata kunci: identififkasi, Bumbu Tradisional, Bali Aga

\begin{abstract}
The purpose of this research was to describe the traditional Balinese seasoning in Bali Aga village in Buleleng regency. The seasoning used in Bali Aga village used in special foods and regular foods. The type of this research is descriptive and was carried out in Bali Aga village in Buleleng regency. The techniques used in selecting the informants are (1) Puspusive samples and (2) Random samples. The data collection techniques are used (1) observation and (2) interviews. The research instruments used are (1) observation sheets and (2) interview guides. In analyzing the data, this research was using qualitative descriptive techniques. The results showed that the traditional seasoning that used in Bali Aga village in Buleleng regency were Base gede/wayah, base selem, base bawang jahe, base colok, base manis, sambal mba, sambal nyuh, pasan ketekan (wewalungan), base tetekan (isinbet/alas), base pengenep, base uyah sereh tabia, base sune cekuh, base pelalah, base kables, base plecing, base serosop, base kela dan base nyengluh.
\end{abstract}

Keywords: Identification, Traditional seasoning, Bali Aga

\section{PENDAHULUAN}

Bali dikenal di mancanegara karena kearifan lokal yang masih sangat terjaga sampai saat ini dan alam yang sangat indah. Salah satu hal yang masih dijaga sebagai warisan leluhur dan terkenal dipulau ini adalah tentang makanan tradisional. Kuliner tradisional Bali sebagai wisata kuliner (culinary tourism) yang berkaitan dengan makanan khas daerah
Bali yang diartikan sebagai makanan yang diolah dan dibuat oleh masyarakat lokal Bali secara turun temurun menggunakan perpaduan bahan pangan dan bumbu (basa) yang memiliki rasa,aroma, warna, dan tekstur yang spesifik yang tidak dimiliki oleh daerah lainnya

Makanan tradisional Bali yang sangat terkenal diantaranya ayam betutu, serombotan, tipat santok, rujak bulung, sate lilit, sambal matah, dan juga blayag. 
Semua hidangan tersebut meggunakan bumbu-bumbu tradisional khas Bali. Semua hidangan tersebut meggunakan bumbu-bumbu tradisional khas Bali.

Bumbu merupakan bagian dari pengolahan hidangan yang mampu memberikan memberikan rasa aroma dan warna yang dapat menimbulkan selera. Berbagi jenis bumbu di Bali disebut lakar basa. atau untuk memudahkan disebut basa. Setiap daerah yang ada di Pulau Bali mempunyai hidangan khas yang berbeda-beda sehingga bumbu yang digunakan pun berbeda. Bahkan dalam satu kabupaten setiap kecamatan akan memiliki ciri khas bumbu tersendiri meskipun nama bumbunya sama tetapi ada beberapa bahan yang di daerah satu menggunakan di daerah lain tidak menggunakan salah satu bahan bumbu tersebut. Kabupaten Buleleng adalah Kabupaten yang terluas di Pulau Bali. Pada kehidupan masyarakatnya dikenal dengan istilah Bali Aga, yang mana penduduk Bali Aga ini mengakui diri mereka adalah penduduk asli pulau Bali, jadi mereka sudah ada jauh sebelum pengaruh atau invansi dari kerajaan Majapahit datang ke Bali. Sejumlah desa yang tergolong Bali Aga di Kabupaten Buleleng yaitu di Kecamatan Banjar seperti Desa Sidatapa, Desa Pedawa Desa Cempaga, dan Desa Tigawasa. Di Kecamatan Tejakula seperti Desa Sembiran dan Desa Julah. Semua desa Bali Aga memiliki tradisi yang unik. Keunikan Desa Bali Aga mempengaruhi wisata kuliner yang berkaitan dengan bumbu yang khas. Bumbu tersebut antara daerah satu dengan yang laiinya dengan nama bumbu yang sama memiliki perbedaan. Setiap desa dalam satu wilayah kecamatan mempunyai kekhasan hidangan masing-masing. Hal ini bisa dimungkinkan oleh faktor-faktor seperti letak geografis desa, seperti desa yang berdekatan dengan pantai, maka hidangannya pun lebih banyak bersumber dari hasil-hasil laut. (Sukerti, Ni Wayan, dkk. 2016)

Hidangan Bali yang beragam akan membedakan bumbu yang digunakan contohnya seperti betutu bebek (daging bebek yang di oven tradisional dengan bumbu khas dari Ubud), sate platter (sate serapah bumbu Bali dengan daging babi), siap base kalas (ayam dengan bumbu pedas dan bersantan), ayam pelalah (ayam suir dengan bumbu yang tajam yaitu cabai dan jeruk purut). Velyniawati, dkk. 2015)

Makanan tradisional khas Bali menggunakan bumbu tradisional khas daerah. Bumbu tradisional khas Bali disebut basa. Basa adalah bumbu yang membuat masakan menjadi lezat. Bahanbahannya terdiri dari bumbu pokok dan bumbu pelengkap. Bumbu pokok terdiri dari bawang merah, bawang putih, isen, kunyit, jahe, cekuh, dan pengolahannya dilakukan dengan cara melumatkan. Dan bumbu pelengkap terdiri dari cabai, terasi, gamongan, bangle, tabia bun, jangan ulam (daun salam), jebug garum, kemiri, dan gula

Makanan tradisional khas Bali menggunakan bumbu tradisional khas daerah. Bumbu tradisional khas Bali disebut basa. Basa adalah bumbu yang membuat masakan menjadi lezat. Bahanbahannya terdiri dari bumbu pokok dan bumbu pelengkap. Bumbu pokok terdiri dari bawang merah, bawang putih, isen, kunyit, jahe, cekuh, dan pengolahannya dilakukan dengan cara melumatkan. Dan bumbu pelengkap terdiri dari cabai, terasi, gamongan, bangle, tabia bun, jangan ulam (daun salam), jebug garum, kemiri, dan gula. Ada beberapa bahan yang unik digunakan dalam pembuatan bumbu khas Bali yang tidak dijumpai di daerah lain. bumbu tradisional khas Bali pada setiap daerah ada perbedaan pada bahan dan jumlah yang digunakan. Selain itu, bumbu yang sama dapat digunakan pada makanan yang berbeda. Bumbu-bumbu tersebut dalam pemilihan bahan baik penambahan bahan atau pengurangan bahan tertentu akan berbeda antara daerah satu dengan yang lainnya bahkan bumbu-bumbu tersebut dengan bumbu yang sama bisa digunakan pada makanan yang berbeda sesuai dengan kebiasaan turun temurun di daerah tersebut. Maka permasalahan diatas mendapatkan rumusan masalah yang di dapatkan yaitu. Bagaimana penggunaan bumbu khas tradisional Bali pada Desa Bali Aga di 
Kabupaten Buleleng. Dari hal tersebut peneliti mengangkat sebuah judul "Identifikasi Bumbu Khas Tradisional Bali Pada Desa Bali Aga Di Kabupaten Buleleng".

\section{METODE PENELITIAN}

Jenis penelitian ini adalah Deskriftif yaitu suatu metode dalam meneliti status sekelompok manusia, suatu objek, suatu set kondisi, suatu sistem pemikiran ataupun suatu kelas peristiwa pada masa sekarang (Nazir, 1988: 63)..

Penelitian ini dilaksanakan Lokasi penelitian ini di Desa Bali Aga Kabupaten Buleleng, dipilih 2 Kecamatan yaitu Kecamatan Banjar dan Kecamatan Tejakula dengan menggunakan purposive sampling (sampel terpilih). Kemudian sampel desa yang dipilih dari kecamatan tersebut dipilih berdasarkan random sampling agar semua desa mendapat perlakuan yang sama.Lokasi dalam penelitian ini dilakukan di 2 (dua) desa. yaitu Desa Pedawa dan Desa Sembiran. Lokasi ini dipilih atas dasar pertimbangan (1) Desa yang terpilih sebagai tempat penelitian adalah desa yang terkenal dengan makanan khas daerahnya dan kebiasaan yang unik dimasing-masing desa. (2) Makanan khas setiap daerah yang ada pada Desa Bali Aga di Kabupaten Buleleng berasal dari potensi alam disekitar. Sedangkan waktu pelaksanaan mulai bulan November 2019 sampai dengan bulan Januari 2020 ..

Informan dalam penelitian ini ditentukan dengan teknik Penelitian ini ditentukan dengan 2 teknik sampling yaitu, purposive sampling dan snowball sampling. Purposive sampling adalah teknik sampel yang didasarkan atas ciri" tertentu yang dipandang mempunyai sangkut paut yang erat dengan populasi yang diketahui sebelumnya. Dengan kata lain unit sampel yang dihubungi disesuaikan dengan kriteria-kriteria tertentu yang diterapkan berdasarkan tujuan penelitian (Morrisan, 2014 : 117). Snowbal sampling adalah dimana peneliti secara acak menghubungi beberapa responden yang memenuhi beberapa kriteria (qualified volunteer sample) dan kemudian meminta responden bersangkutan untuk merekomendasikan teman, keluarga, atau kenalan yang mereka ketahui memenuhi kriteria yang dijadikan responden. Morissan (2014 : 120. Informan dalam penelitian ini adalah orang-orang yang dianggap tahu tentang bumbu khas tradisional Bali pada Desa Bali Aga di Kabupaten Buleleng. Karakteristik informan yang menjadi pertimbangan antara lain:

1. Tokoh masyarakat di wilayah sampling penelitian yang tahu seni kuliner Bali

2. Ibu-ibu rumah tangga di wilayah sampling penelitian

3. Pengusaha rumah makan maupun industri kecil yang bergerak di bidang makanan.

Metode dalam pengumpulan data ini yaitu Metode observasi dan metode wawancara. Metode observasi merupakan pengamatan dan pencatatan secara sistematik terhadap gejala yang terdapat pada objek penelitian (Margono, 2009 : 158). Kemudian Metode wawancara merupakan suatu bentuk dialog yang dilakukan oleh pewawancara untuk memperoleh informasi dari telewicara (Trianto, 2011 : 266). Metode ini sangat penting untuk melengkapi data dari hasil pengamatan. Metode wawancara ini digunakan untuk memperoeh data terkait nama bumbu, bahan bumbu, jumlah, proses, dan penggunaan pada makanan di Kabupaten Buleleng. Teknik wawancara yang digunakan dalam penelitian ini adalah wawancara bebas terpimpin yakni pengumpulan data untuk mendapatkan informasi secara langsung dengan mengajukan pertanyaan kepada para informan berdasarkan pedoman yang telah disiapkan terlebih dahulu. Pedoman wawancara tersebut hanya mencantumkan pokok-pokok permasalahan yang akan ditanyakan dan selanjutnya pertanyaan-pertanyaan itu dikembangkan secara bebas sesuai kepentingan penelitian. 


\section{HASIL DAN PEMBAHASAN}

Sesuai dengan tujuan penelitian yaitu untuk mendeskripsikan penggunaan bumbu khas tradisional Bali pada Desa Bali Aga di Kabupaten Buleleng sebagai berikut:

a. Base gede atau base wayah Base gede atau base wayah adalah bumbu yang terdiri dari laos, jahe, kunyit, kencur, bawang merah, bawang putih, merica, ketumbar, cabai, terasi, daun salam, sereh, garam, dan tabia bun (Remen I Ketut, 1987). Base gede atau base wayah pada Desa Bali Aga terdiri dari laos, jahe, kunyit, kencur, bawang merah, bawang putih, merica, ketumbar, cabai, terasi, daun salam, sereh, garam, dan tabia bun. Bahan bumbu yang digunakan ada perbedaan di setiap desa seperti di Desa Pedawa menggunakan sedikit merah, yang dipengaruhi oleh letak geografis masing-masing desa seperti di Desa Pedawa menggunakan sedikit gula merah, Desa Pedawa terkenal dengan penghasil gula merah yang bertujuan agar bumbu atau base gede yang dihasilkan tidak terlalu pedas. Pada Desa Sembiran base gede tidak menggunakan ketumbar, daun jinten, dan gula Bali karena bumbu ketumbar digunakan untuk bumbu ikan yang bumbunya tidak selengkap base gede. Bumbu daun jinten digunakan untuk pembutan sate tetapi bumbunya berbeda dengan bumbu base genep, dan gula Bali tidak digunakan karena akan mempengaruhi warna dan rasa. Ukuran bumbu yang digunakan juga terdapat perbedaan antara daerah satu dengan daerah lain karena ukuran bumbu akan disesuikan dengan jumlah bahan makanan yang akan dibumbui dan disesuaikan dengan jenis makanan yang akan dibumbui. Teknik pengolahan base gede/wayah yaitu dirajang dan diintuk. Base gede /wayah pada Desa Bali Aga di Kabupaten Buleleng digunakan untuk jukut, lawar, urab-uraban, dan juga olahan babi guling.

b. Base selem terdiri dari kemiri, bawang putih, kencur, merica, ketumbar, cabai kecil, terasi, sereh, daun jinten, daun salam, daun wangen, kulit kelapa yang dibakar, dan garam (Remen I Ketut, 1987).. Bumbu selem pada desa Bali Aga terdiri dari kemiri, bawang putih, kencur, merica, ketumbar, cabai kecil, terasi, sereh, daun jinten, daun salam, daun wangen, kulit kelapa yang dibakar, dan garam dan bumbu selem tidak semua desa menggunakan pada Desa Bali Aga seperti Desa Sembiran karena bumbu ini tidak pernah digunakan baik itu untuk sehari hari maupun untuk upacara agama. Base selem tidak digunakan disebabkan karena bumbu ini tidak dikenal di masyarakat Desa Sembiran. Base selem digunakan di Desa Pedawa. Teknik Pengolahan base selem yaitu dirajang dan diintuk. Base selem pada Desa Bali Aga di gunakan untuk uraban paku dan sate nyuh selem.

c. Base bawang jahe Base bawang jahe adalah bumbu tradisional Bali yang terdiri dari kemiri, bawang merah, jahe, bawang putih, cabai besar, tearsi, sereh, daun jinten, daun salam, daun wangen, merica, ketumbar, kulit kelapa yang dibakar (Remen I Ketut , 1987). pada Desa Bali Aga di Kabupaten Buleleng memiliki bahan bumbu yang berbeda seperti pada Desa Pedawa terdiri dari kemiri, bawang merah, jahe, bawang putih, cabai besar, terasi, sereh, daun jinten, daun salam, merica, ketumbar, dan garam dengan ukuran bahan bumbu bawang merah dan jahe yang paling banyak jumlahnya sedangkan bahan yang lain ditambahakan sedikit sedangkan pada Desa Sembiran bahan base bawang jahe hanya menggunakan bawang merah, jahe, terasi, daun salam, dan garam. Teknik pengolahan base bawang jahe yaitu dirajang dan diintuk. Base bawang jahe pada Desa Bali Aga di Kabupaten Buleleng digunakan pada makanan yang berbeda pada Desa Pedawa di gunakan untuk Pesan taen lengis paku, jukut bebalungan sedangkan pada Desa Sembiran digunakan untuk Tum be celeng, tum be siap, tum be pasih, be siap bawang jae.

d. Base colok terdiri dari laos, jahe, kunyit, kencur, bawang merah, bawang putih, merica, ketumbar, cabai, terasi, daun salam, sereh, garam, kemiri, minyak kelapa dan tabia bun (Remen I Ketut , 1987 pada desa Bali Aga namun bahan bumbu yang digunakan ada perbedaan di setiap desa seperti di Desa Pedawa 
menggunakan sedikit gula bali asli daerah yang bertujuan agar bumbu atau base colok yang dihasilkan tidak terlalu pedas. Pada Desa Sembiran base colok tidak menggunakan ketumbar, daun jinten, dan gula bali karena bumbu ketumbar digunakan untuk bumbu ikan yang bumbunya tidak selengkap base colok. Ukuran bumbu yang digunakan juga terdapat perbedaan antara daerah satu dengan daerah lain. Teknik pengolahan base colok yaitu dirajang dan diintuk. Base colok digunakan pada makanan yang sama dan berbeda pada Desa Bali Aga di Kabupaten Buleleng seperti pada Desa Pedawa digunakan untuk Tum putih be siap, lawar putih sedangkan pada Desa Sembiran digunakan untuk Lawar putih, Tum perapah.

e. Base manis terdiri dari kelapa dibakar, bawang putih, kencur, cabai kecil, merica , ketumbar, terasi, sereh, cabai besar, daun salam, gula bali, dan garam Bahan bumbu kencur pada Desa Sembiran tidak menggunakan karena membuat base manis menjadi tengik. Teknik pengolahan base manis pada diintuk dan dirajang. Base colok pada Desa Bali Aga di Kabupaten Buleleng di gunakan untuk ayam kecap, babi kecap, sate manis.

f. Sambal Mba terdiri dari bawang merah, bawang putih, cabai, terasi, garam. Bahan bumbu yang digunakan terdapat perbedaan seperti di Desa Sembiran menggunakan sedikit kunyit tanpa menggunakan agar tampilan dari sambal mba menjadi coklat kekuningan dan sambal mba ini tidak menggunakan bawang putih. Sedangkan di Desa Pedawa sambal mba tidak menggunakan kunyit tetapi menggunakan bawang putih. Teknik pengolahan sambal mba yaitu dirajang (diiris). Sambal mba pada Desa Bali Aga di Kabupaten Buleleng di gunakan untuk urab-uraban atau lawar seperti lawar putih, lawar barak, lawar nangka, lawar kacang.

g. Sambal nyuh terdiri dari Kelapa, laos, jahe, kunyit, kencur, bawang merah, bawang putih, merica, ketumbar, cabai, terasi, daun salam, sereh, garam, dan minyak kelapa. Bahan bumbu yang digunakan pada Desa Sembiran tidak menggunakan jahe dan kunyit karena bumbu ini ditambahkan pada bumbu yang lain sedangkan pada Desa Pedawa sambal nyuh menggunakan semua bumbu seperti pemaparan diatas. Teknik pengolahan sambal nyuh yaitu diintuk. Sambal nyuh pada Desa Bali Aga di gunakan untuk Bayam sambal nyuh dan Engseban timun.

h. Basan ketekan (wewalungan) terdiri dari bawang putih, kencur, cabai kecil, merica, ketumbar dan garam. Bumbu ini tidak dikenal di Desa Sembiran. Basan ketekan (wewalungan) digunakan pada Desa Bali Aga di Kabupaten Buleleng yaitu di Desa Pedawa. Teknik Pengolahan basan ketekan yaitu dirajang dan diintuk. Basan ketekan (wewalungan) pada Desa Pedawa di gunakan untuk jukut balung.

i. Basan ketekan (isin bet/alas) terdiri dari bawang putih, laos, cabai kecil, merica, ketumbar dan garam. Bumbu ini tidak dikenal di Desa Sembiran. Basan ketekan (isin bet/alas) digunakan pada Desa Bali Aga seperti di Desa Pedawa. Teknik Pengolahan basan ketekan yaitu dirajang dan diintuk. Basan ketekan (wewalungan) pada Desa Pedawa di gunakan untuk jukut balung ares.

j. Base pengenep terdiri dari Base serbuk (merica, ketumbar yang sudah dihalus), base limo (limo, daun jeruk sambel diiris halus). Base pengenep pada Desa Bali Aga menggunakan semua bahan tersebut. Base pengenep pada Desa Bali Aga di Kabupaten Buleleng digunakan sebagai bahan penyedap alami.

k. Base uyah sere tabia terdiri dari garam, terasi, cabai, jeruk limo. Teknik pengolahan base uyah sere tabia yaitu dirajang dan dibejek. Base uyah sere tabia pada Desa Bali Aga di Kabupaten Buleleng bumbu ini digunakan di Desa Sembiran untuk bumbu ikan bakar dan sama-sama digunakan untuk be gorengan dan pelengkap makanan lainnya.

I. Base sune cekuh terdiri dari bawang putih, kencur, garam, dan terasi Teknik pengolahan base sune cekuh yaitu dirajang dan diulek. Base sune cekuh pada Desa Bali Aga di Kabupaten Buleleng digunakan pada makanan yang berbeda seperti di Desa Pedawa hanya 
digunakan untuk kentang sune cekuh dan di Desa Sembiran untuk ikan goreng dan ikan bakar.

m. Base pelalah terdiri dari base pelepah ditambah kencur dan santan. Base pelalah pada Desa Bali Aga di Kabupaten Buleleng digunakan sebagai pelengkap lauk pauk. Base pelalah terdiri dari cabai kecil dan garam. Base pelalah tidak semua desa menggunakan pada Desa Bali Aga seperti Desa Pedawa tidak mengenal base pelalah. Base pelalah dikenal di Desa Sembiran sebagai pelengkap lauk pauk. Teknik Pengolahan base pelalah yaitu dirajang dan dicampur.

n. Base kables terdiri dari cabai, cabai besar, bawang putih, terasi, garam, dan limo Teknik pengolahan base kables yaitu diulek. Base kables pada Desa Bali Aga di Kabupaten Buleleng digunakan untuk plecing kables dan tipat kables

o. Base plecing terdiri dari cabai, cabai besar, bawang putih, terasi, garam, tomat, dan limo Pada Desa Bali Aga bumbu yang digunakan sama seperti penjelasan tersebut namun Base plecing di Desa Sembiran tidak menggunakan tomat karena jika ditambahkan tomat rasa pedas dari plecing akan berkurang sedangkan, pada Desa Pedawa menggunakan bahan tomat. Teknik pengolahan base kables yaitu diulek. Base Plecing pada Desa Bali Aga digunakan untuk plecing kangkung, plecing kacang panjang, plecing sawi, dan plecing buncis.

p. Base serosop terdiri dari kemiri, kencur, cabai, bawang merah, bawang putih, merica, garam, dan daun salam serta kunyit. Base serosop pada Desa Sembiran tidak menggunakan merica namun lebih banyak menggunakan cabai kecil karena pedas dari cabai lebih sehat daripada pedas dai merica. Teknik pengolahan base serosop yaitu dirajang dan diintuk. Base setosop pada Desa Bali Aga digunakan untuk serosop pusuh biu dan serosop nangka.

q. Base kela terdiri dari bawang merah, bawang puth, cabai, kunyit, kencur, laos, jahe, kemiri, ketumbar, merica hitam, tabia bun, pala jangu, terasi. Base kela digunakan pada Desa Bali Aga di Kabuapaten Buleleng yaitu di Desa Pedawa dengan bahan bumbu seperti penjelasan tersebut. Teknik Pengolahan base kela yaitu dirajang dan diintuk.. Base kela pada Desa di gunakan untuk kulit be guling.

r. Base nyangluh terdiri dari kemiri, laos, ketumbar, tabia bun, kelapa dirajang halus Teknik pengolahan base nyangluh yaitu dirajang dan diintuk. Base nyangluh pada Desa Bali Aga di Kabupaten Buleleng digunakan pada Desa Pedawa untuk jejeruk don belimbing dan Desa Sembiran untuk lawar nyuh dan lawar kulit.

\section{KESIMPULAN DAN SARAN}

Berdasarkan hasil penelitian indentifikasi bumbu khas tradisional Bali pada Desa Bali Aga di Kabupaten Buleleng maka dapat disimpulkan bahwa Bumbu Bali pada Desa Bali Aga di Kabupaten Buleleng terdiri dari Base gede/wayah, base selem, base bawang jahe, base colok, base manis, sambal mba, sambal nyuh, basan ketekan (wewalungan), basan ketekan (isin bet/alas), base pengenep, base uyah sere tabia, base sune cekuh, base pelalah, base kables, base plecing, base serosop, base kela, dan base nyangluh.

\section{SARAN}

Berdasarkan hasil yang diperoleh dari penelitian ini bahwa Untuk masyarakat yang ada pada Desa Bali Aga di Kabupaten Buleleng agar dapat lebih memanfaatkan sumber daya alam yang dimiliki dan bahan-bahan bumbu yang memungkinkan bisa hidup di daerah tersebut agar dikembangkan sehingga tidak semua bumbu dibeli. Sehingga pemanfaatan bahan untuk bumbu bisa optimal.Hygiene dan sanitasi dan pembuatan bumbu juga harus diperhatikan seperti alas pada saat pembuatan bumbu, kebersihan alat dan bahan bumbu yang akan mempengaruhi kebersihan makanan.Upaya masyarakat pada Desa Bali Aga di Kabupaten Buleleng dalam melestarikan bumbu tradisional Bali agar tetap dijaga dan dipertahankan, sehingga bumbu tradisional Bali tetap lestari 


\section{Daftar pustaka}

Margono, S. (2009). Metodologi Penelitian Pendidikan Komponen MKDK. Jakarta : PT Rineka Cipta.

Morrissan.2014 Metode Penelitian Survey. Jakarta: Kencana Prenadamedia Group,

Nazir. $1988 . \quad$ (online).( http:I/merlitafutrianaO.blogspot.c om/p/wawancara.html, diakses 14 Agustus 2019)

Remen, I Ketut. 1987. O/ah-O/ahan Paebatan Bali. Dcnpasar: Banjar Sila Danna Nyuhgading Mengwitani

Sukerti, Ni Wayan, dkk. 2016. Reinventarisasi Makanan Tradisional Buleleng Sebagai Upaya Pelestarian Seni Kuliner Bali. Jurnal Ilmu Sosial dan Humaniora. 5(1):

Trianto. (2011). Panduan Lengkap Penelitian Tindakan Kelas.Jakarta: Prestasi Putakarya

Velyniawati, Putu, dkk. 2015: Tingkat Peneriman Wisatawan Asing Terhadap Makanan Tradisional Bali. Jurnal IImu Gizi. 6(1): 5865 